\title{
PEDAGOGIAS CULTURAIS NO CAMPO MUSICAL: o caso da Música Instrumental Gaúcha
}

\author{
Felipe Batistella Alvares \\ Instituto Federal de Educação, Ciência e Tecnologia do Rio Grande do Sul - Campus Sertão \\ - IFRS, Brasil \\ Rosa Maria Hessel Silveira \\ Universidade Federal do Rio Grande do Sul - UFRGS, Brasil
}

\begin{abstract}
Resumo
Ao lado de uma ampla literatura no âmbito da Educação que investiga processos de aprendizagem em espaços escolares, mais recentemente outras práticas e artefatos culturais que assumem uma função pedagógica, têm despertado interesse na pesquisa acadêmica. Neste sentido, o presente artigo, com base no campo dos Estudos Culturais, lança mão do conceito de Pedagogias Culturais, o qual aponta que os processos educativos podem ocorrer em diferentes instâncias, não se limitando às escolares. Seu objetivo é analisar o modo como acontecem as aprendizagens de músicos que transitam na Música Instrumental Gaúcha, entendendo este gênero musical como um local pedagógico. A partir da análise do material empírico, constituído por entrevistas semiestruturadas realizadas com quatro músicos atuantes e publicamente reconhecidos no gênero, o estudo observou que os diferentes espaços e artefatos culturais ligados à cultura e à música gaúcha, como Centros de Tradições Gaúchas e Festivais Nativistas, presentes em toda a trajetória destes músicos, têm repercussões na promoção de situações de aprendizagem e na produção de saberes.
\end{abstract}

Palavras-chave: Pedagogia cultural; Música instrumental gaúcha; Identidade; Estudos culturais em educação; Educação musical.

\begin{abstract}
Along with a wide literature on education that investigates the learning processes in school spaces, recently other practices and cultural artifacts that take over the pedagogical function have aroused interest over academic studies. In that sense, this paper, based on the field of Cultural Studies, works with the concept of Cultural Pedagogies, which points out that educational processes may occur in other domains, not limited to the school's. The paper aims at analyzing how the learning of musicians who passed through the Gaucho's Instrumental Music takes place, understanding this musical genre as a pedagogical place. Based on the analysis of the empirical material, constituted of semi-structured interviews with four active and publicly recognized musicians of the genre, the study noted that the different spaces and cultural artifacts associated to the gaucho's culture and music, as the Gaucho's Traditions Center and the Nativistas Festivals, present through the whole path of these musicians, are effective in the promotion of learning and knowledge production situations.
\end{abstract}

Keywords: Cultural pedagogy; Gaucho's instrumental music; Identity; Cultural studies in education; Musical education. 


\section{Palavras iniciais: pedagogias culturais e Música Instrumental Gaúcha1}

Constitui uma tradição no campo acadêmico da Educação a realização de pesquisas que adentram os espaços escolares para investigar as práticas reconhecidamente pedagógicas, com o intuito de examinar sua realização, adequação, eficácia etc. Para além desta tradição, entretanto, não é nova a constatação de que, gradativamente, práticas culturais extraescolares que também funcionam como pedagógicas vêm recebendo um olhar mais atento do ambiente acadêmico. Tal fato ocorre, primeiramente, em função de diversas mudanças pelas quais o mundo contemporâneo vem passando e que vêm promovendo novos e diferentes espaços de aprendizados, como explicita Silva:

O que caracteriza a cena social e cultural contemporânea é precisamente o apagamento de fronteiras entre instituições e esferas anteriormente consideradas como distintas e separadas. Revoluções nos sistemas de informação e comunicação, como a Internet, por exemplo, tornam cada vez mais problemáticas as separações e distinções entre o conhecimento cotidiano, o conhecimento da cultura de massa e o conhecimento escolar (Silva, 2004, p. 142).

As transformações referidas por Silva não só desencadearam o esmaecimento de fronteiras entre conhecimento escolar, conhecimento proporcionado pelas mídias e conhecimento advindo das experiências cotidianas, como também provocaram o interesse pelo estudo do que se passou a denominar "Pedagogias Culturais". Andrade \& Costa (2017), ao realizarem detido estudo sobre a emergência e constituição do conceito no Brasil, referem que a circulação do termo tem uma história de vinte anos, sendo que sua emergência se deu no campo dos Estudos Culturais em Educação, justamente o campo teórico em que se situa o presente estudo. As autoras registram também a produtividade da expansão da ideia da multiplicidade de lugares de aprendizagem, conceito que foi sendo matizado em muitos autores e que, justamente, veio a desembocar na exploração acadêmica das pedagogias culturais.

Os estudos que lançam mão do conceito de pedagogias culturais justamente nos provocam a refletir não só a respeito dos lugares como também dos modos como os sujeitos realizam diferentes aprendizagens. É necessário considerar que as transformações já citadas promoveram um deslocamento do modo como os alunos tomam contato com conhecimentos de diferentes campos (Biologia, História, Física e Química, por ex.), em aprendizagens que ocorrem à margem dos métodos formais de ensino que a escola insiste em perpetuar. No campo da música - que será focalizado neste estudo - e, mais especificamente, quanto aos modos como os sujeitos desenvolvem suas habilidades para tocar um instrumento, para compor, ou para gravar suas músicas, estas fronteiras são ainda mais “desbotadas”, já que está envolvida uma prática que, com muito mais frequência (em relação a outros campos de saber), é realizada por meninas e meninos em suas casas, com seus amigos do bairro, ou em suas "bandas de garagem". 
Neste contexto, a escola deixa de ser pensada como exclusiva enquanto espaço de produção e transmissão de saberes, e outros ambientes sociais e/ou meios de comunicação, que também promovem interações humanas e dispersam significações, ganham relevância no âmbito educativo. E é a partir de estudos que consideram a centralidade da cultura, que este texto se debruça sobre como determinadas pedagogias culturais atuam em processos de aprendizagem musical, tomando o conceito a partir de uma citação já clássica de Steinberg (1997).

O termo "pedagogia cultural" refere-se à ideia de que a educação ocorre numa variedade de locais sociais, incluindo a escola, mas não se limitando a ela. Locais pedagógicos são aqueles onde o poder se organiza e se exercita, tais como bibliotecas, TV, filmes, jornais, revistas, brinquedos, anúncios, videogames, livros, esportes, etc. (Steinberg, 1997, p.101-102).

No âmbito da Música Instrumental Gaúcha $\left(\mathrm{MIG}^{2}\right)$, foco deste estudo, uma hipótese prévia é a de que os modos como os músicos aprendem a tocar, compor e performar acontecem nos ambientes de suas práticas: nos palcos de festivais, nos $\mathrm{CTGs}^{3}$, nos estúdios de música entre outros. Tal hipótese advém da constatação de que a MIG, de forma semelhante a outros gêneros de música popular, não tem sido contemplada nos currículos acadêmicos de modo amplo e sistemático; tais aspectos condicionam as possibilidades de aprendizagem de músicos aspirantes às escutas fonográficas, às escutas radiofônicas, ao assistir um show ou à troca de experiências com músicos veteranos, entre outros.

A fundamentação deste trabalho está inspirada no campo dos Estudos Culturais (EC) e suas articulações com a Educação, sendo que alguns conceitos teóricos utilizados por esse campo orientam o presente estudo, como o entendimento amplo de 'cultura', não mais restrito a obras tidas como de excelência, que se distinguiriam intrinsecamente de todas as outras. Dessa forma, pretendemos propiciar uma reflexão a respeito da educação musical em espaços não institucionalizados de educação.

Partindo desta perspectiva, postulamos a Música Instrumental Gaúcha como um local pedagógico, que é operacionalizado por instâncias como Centros de Tradições Gaúchas, festivais nativistas, por artefatos midiáticos como discos, rádio, televisão, internet, entre outros, os quais formam "sistemas de significação implicados na produção de identidades e subjetividades" (Silva, 2004, p. 142) daqueles/as que participam neste meio como instrumentistas, compositores, intérpretes e demais envolvidos. A questão da identidade (a busca por uma) é um aspecto muito relevante para os músicos; a necessidade de constituirse enquanto um artista que apresenta uma identidade própria - ou, digamos, uma novidade estética -, é uma demanda constante na vida desses sujeitos. Esse empreendimento é realizado no âmbito do sonoro musical, ou seja, a centralidade deste processo está nos esforços em criar uma sonoridade própria.

Apresentamos, aqui, sonoridade como um traço identitário de um artista ou de uma banda, engendrada no interior de um contexto cultural, o qual cria condições de possibilidades para os "modos de soar" de um álbum, de um músico ou de uma música. Sua 
emergência se dá nas relações estabelecidas entre os momentos de produção e de consumo, o que perpassa os modos de criação/composição, performance, gravação e escuta musical. As resultantes (discos, espetáculos etc.) são consumidas a partir da ideia dos gêneros musicais, que não apenas categorizam as diferentes sonoridades, mas também ajudam a dar sentido a elas. Segundo Frith, o conceito de gênero musical indica

como as formas musicais são apropriadas para constituírem sentido e valor, que determinam os vários tipos de julgamento, que determinam a competência das diferentes pessoas de fazer comentários. É através dos gêneros que nós experimentamos a música e as relações musicais, que nós unimos o estético e o ético (Frith, 2003, p. 95).

Os gêneros musicais são centrais neste estudo como uma instância que atua na atribuição de significados às sonoridades, delineando o que é som e o que é ruído. Este processo não tem a capacidade de estabilizar as significações, mas mobiliza a cadeia de negociações entre a produção e o consumo simbólico das sonoridades, e constitui um sistema que organiza determinados elementos que o músico poderá e/ou deverá aprender (e usar) para criar sua música, realizar sua performance, cativar seu público etc. Esta concepção amplia o entendimento a respeito de pedagogia, permitindo pensarmos o gênero MIG como um campo pedagógico que apresenta um currículo cultural e promove situações de aprendizagens, ainda que a palavra (escrita ou falada), tão central em outros processos educativos, não pareça ocupar um posto central no gênero, o que seria o caso, se estudássemos a música gaúcha cantada, com suas letras que, via de regra, enaltecem discursivamente a figura do 'gaúcho' rural e outros temas correlatos.

A partir destes pressupostos - sobre cultura, sobre pedagogias culturais e sobre Música Instrumental Gaúcha -, o objetivo do presente artigo é buscar compreender como músicos que transitam pela MIG narram suas aprendizagens, tanto iniciais quanto aquelas empreendidas no âmbito da atuação profissional, e desenvolvem seus trabalhos autorais no campo desse gênero musical. A ideia é analisar como é empreendida a trama das aprendizagens destes músicos, com o intuito de responder à seguinte pergunta: quais os efeitos pedagógicos que diferentes instâncias, artefatos e práticas culturais que permeiam a MIG têm no processo de formação das identidades desses músicos?

Para a constituição do material empírico de análise, foram realizadas entrevistas semiestruturadas com os músicos Renato Borghetti, Marcello Caminha, Maurício Marques e Fernando Graciola ${ }^{4}$. A escolha dos músicos se pautou por vários critérios. Em primeiro lugar, Renato Borghetti, Marcello Caminha, Maurício Marques são músicos com carreiras consolidadas dentro do que se costuma chamar de Música Instrumental Gaúcha. A escolha de Borghetti e de Caminha se deu pelo entendimento de que ambos representam de uma maneira bastante significativa alguns dos "modos de soar" dentro da MIG feita ao acordeom e ao violão respectivamente, ou seja, possuem um repertório mais "encaixado" nas formas canônicas deste gênero. Já os violonistas Maurício Marques e Fernando Graciola foram escolhidos pelo fato de possuírem um repertório com maiores hibridações, considerando seu 
maior trânsito entre a Música Erudita, o Choro, a MPB, o Jazz e a Música Gaúcha. Nas entrevistas realizadas - gravadas em áudio - os questionamentos foram em relação ao entendimento de cada músico a respeito da constituição da cultura, dos sujeitos e da Música Instrumental Gaúcha e da influência destas instâncias no trabalho artístico/autoral dos entrevistados. Após a transcrição das mesmas, efetuou-se uma análise e aproximação entre suas respostas, que foram, então, agrupadas nos dois eixos que seguem: os caminhos da aprendizagem e o trabalho autoral.

\section{Os caminhos da aprendizagem}

Ao observar a história de vida que os músicos narraram nas entrevistas, evidencia-se que o processo de construção das suas identidades está diretamente/fortemente ligado ao contexto vivido, ao ambiente 'natural' de florescimento da música gaúcha, o qual, no caso aqui estudado, são extramusicais, pelo menos em um primeiro momento.

Antes de tocar, eu declamava em rodeios. [...] Talvez por isso o gosto pela música gaúcha, e ser um norte maior dos meus trabalhos atuais, é porque antes do instrumento tinha a palavra, a poesia, o CTG (Graciola).

A mãe e o pai sempre foram ligados ao movimento tradicionalista (CTG/MTG). Então, eu me criei dentro do Movimento Tradicionalista Gaúcho. Meu clube, o círculo de amizades, quase todo, na época, era muito mais o CTG do que a própria escola. O CTG acabava realmente sendo a minha atividade social. Neste início eu não tocava, eu participei da Invernada artística do CTG dançando, mas nunca gostei (Borghetti).

Como podemos perceber, antes de uma iniciação à música (tocar um instrumento, participar de um grupo de música etc.), existe o estabelecimento de um contato com elementos da cultura gaúcha. Isto posto, os CTGs, que são espaços de coletividade e de interação social que acolhem esses sujeitos, apresentaram-lhes um universo simbólico com elementos ligados à representação do local, do regional e do tradicional. Nesses ambientes, a música permeia diversas ações, constituindo eixo central na realização de atividades como ensaios/apresentações de grupos de danças, bailes, concursos de declamação de poesias, entre outras; é nesta trama que emergem possibilidades e oportunidades.

Tinha o gaiteiro da invernada artística [...], que tocava gaita pianada, gaiteiro das danças, ele tinha uma "gaitinha ponto" em casa, e começou a trazer para os ensaios. Daí eu tocava um pouquinho com ele, o que eu tirava em casa, e aí eu comecei a tocar. Logo depois eles criaram a invernada mirim [...], e eu parei com a dança total, e fiquei como gaiteiro da invernada mirim (Borghetti).

Neste trecho da entrevista, Renato descreve o momento em que teve a oportunidade de assumir uma função diretamente ligada à música; o arranjo sociocultural lhe oferece 
determinadas opções para participar/colaborar com a comunidade, entre elas a música, a música gaúcha, a gaita ponto, elementos que irão fazer parte de sua sonoridade em toda sua carreira. Em outras palavras, as produções culturais realizadas por essas comunidades e suas interrelações com os sujeitos configuram-se como algumas das condições de possibilidades iniciais de emergência das identidades desse músico: "Ter uma identidade seria, antes de mais nada, ter um país, uma cidade ou um bairro, uma entidade em que tudo o que é compartilhado pelos que habitam esse lugar se tornasse idêntico e intercambiável" (Canclini, 2008, p.190). O compartilhamento do instrumento, a oportunidade que se abriu para o jovem Borghetti foi possível em função do lugar e da comunidade.

Neste ambiente cultural, seja em CTGs, festivais nativistas ou outros espaços, outro importante elemento de compartilhamento são as escutas musicais Com isso, o sujeito interage com determinadas músicas e gêneros musicais, predominantemente do universo da música gaúcha; os repertórios que são reproduzidos nos alto-falantes, ou executados ao vivo por outros músicos, servem como elemento de identificação e como uma espécie de fonte de sonoridades que o ajudam a formar sua própria identidade musical.

[...] Naquela época frequentava o CTG, ia nos bailes. Ia muito lá em Bagé o conjunto Os Mirins, que tocava, na época, o Oscarzinho (guitarrista), que eu sempre fui fã [...]. Também Os Serranos, que nessa época toca o Ênio Rodrigues. Aliás, os Serranos sempre tiveram esse cuidado de ter bons instrumentistas, principalmente na guitarra e no violão, e os Mirins, nem se fala, porque os três eram bons, né? E eu acho que isso, é uma das coisas que, dentro da área dos conjuntos de baile, foram os dois conjuntos que chamaram a atenção, assim, dos instrumentistas né? Mais que qualquer outro conjunto, mais que os Monarcas, mais que qualquer outro da época, porque tinha os instrumentistas virtuoses. Então eu tinha esse convívio direto, eu era fã, fã, assim demais, comprava os discos [...]. Então a minha avó fazia as pilchas, igual às capas dos conjuntos, para ir nos bailes. Esta é uma vertente forte da minha influência musical (Caminha).

Este excerto nos auxilia a compreender o quanto as escutas podem atuar nas constituições das sonoridades e das identidades dos músicos. As escutas não são neutras, e não são apenas sonoras. As escutas são articuladas com outros elementos do contexto cultural em que elas acontecem. Os sons (musicais) auxiliam na significação - e são significados no interior deste processo de atribuição de sentidos às práticas e aos artefatos culturais utilizados para compor este campo discursivo. Isto, somado a elementos subjetivos próprios, constitui as condições de possibilidades para emergência desse sujeito violonista.

Nota-se, até aqui, que a aprendizagem musical na esfera da MIG é realizada, em certa medida, de forma não sistematizada, ou seja, não há um currículo escolar, mas existe um conteúdo musical culturalmente organizado, que o futuro músico está conhecendo, está praticando e aprendendo (repertório, instrumentos específicos etc.). Entretanto, para além desse ambiente de impregnação musical, à exceção de Renato Borghetti, os outros três entrevistados referiram que também optaram em frequentar aulas de música com professores 
particulares e escolas/conservatórios especializados no ensino musical e também em cursos de graduação.

Renato argumenta que não estudou porque nunca encontrou um professor específico para o seu instrumento; "[...] Eu tirava de ouvido mesmo. Na época não tinha escola específica de gaita ponto. Eu tocava alguma coisa por conta, e outra coisa era tirar dos discos, principalmente o Tio Bilia [...]" (Borghetti). Observe-se que o uso da expressão "tirar de ouvido', no jargão musical cotidiano, refere-se à aprendizagem rítmica/harmônica/melódica de uma música, sem apoio de partitura, apenas por audição e tentativa de reproduzir os sons advindos de registros fonográficos. Vale ressaltar, que, nas décadas de 1970 e 1980, era muito raro ter acesso a vídeos (a exemplo do youtube), onde a aprendizagem poderia ser feita também pela observação visual, restando, na época, apenas a possibilidade da escuta. Tal prática é bastante comum entre os instrumentistas que atuam em música popular.

Já os outros três músicos referem experiências com professores particulares, em conservatórios e também cursos de música em nível de graduação ${ }^{5}$. Especificamente, trazemos aqui um trecho que nos ajuda a compreender o modo como estas experiências acontecem nas trajetórias dos entrevistados.

Depois de um tempo, eu comecei a fazer aula com o Mário Barros em Porto Alegre. Eu saía de Rio Pardo, ia até Porto Alegre, fazia uma hora de aula, voltava para casa, e ia estudando aquilo. Procurei um professor de teoria em minha cidade. E com o Mário Barros eu estudava música clássica. O Mário Barros me mandava tocar Villa-Lobos. E a música gaúcha eu já sabia tocar de ouvido. Isso desenvolveu muito o meu ouvido, essa coisa da prática, de estar sempre em contato com os músicos do CTG. Acabei aprendendo a misturar as coisas desde o início. Tinha duas escolas, a popular e essa clássica, que começou a entrar embasando o que eu já sabia (Marques).

Em nossa análise, averiguamos que, depois de ter passado por momentos de inserção cultural e iniciação ao mundo da música, os músicos passam a frequentar aulas como um meio de dar continuidade aos aprendizados no campo da música. As aulas apresentam um novo universo simbólico, oferecem outros modos de fazer música, outros conteúdos, agora de forma mais sistematizada; estes novos elementos passam a fazer parte do vocabulário musical destes sujeitos, aumentando suas possibilidades de escolha e também de hibridação. Ao observarmos a narrativa de Maurício Marques, quando afirma que aprendeu muito cedo a "misturar" as coisas (a música clássica e a popular), identificamos a ideia da constituição das identidades como uma resultante - não acabada - de múltiplas interpelações que os diversos elementos culturais exercem na produção das identidades dos músicos, e, consequentemente, das sonoridades dos seus trabalhos.

Outro aspecto importante no processo aqui discutido é a atuação profissional prévia à fase em que estes músicos investem numa carreira solo. O músico, quando passa a atuar de forma profissional, é, inevitavelmente, colocado em situações de escolhas em relação aos gêneros musicais. Ele tem opções: tocar música nativista, tocar samba, tocar rock ou tocar jazz, por exemplo. Em cada escolha, é preciso compreender os "modos de soar" que cada 
gênero exige, e buscar o entendimento de seus elementos musicais e a maneira como se deve utilizá-los. No caso da MIG, os festivais nativistas, bares, casas noturnas, os palcos dos CTGs, entre outros, configuram-se em espaços para a atuação dos músicos.

Eu devia ter 16 anos, por aí. Eu comecei a fazer festivais neste meio tempo. Eu conseguia tirar de ouvido as coisas, inventar na hora e executar as coisas. [...] Então, a minha formação foi por aí, uma mistura. Claro, paralelo a isso, tocando em bar, acompanhando qualquer tipo de cantor, os repertórios dos mais diversos. Eu já atuava profissionalmente, já vivia de música (Marques).

Aqui, observa-se que os conhecimentos construídos durante as experiências de atuação profissional são resultado de uma não separação entre as ações de estudar (mesmo que de modo informal) e de atuar. Esta forma de aprender não se dá apenas pelo ato de consumir as informações de um livro (ou de outra fonte), ou em aulas expositivas/palestras. Parafraseando Larrosa (2002), esse é um saber da experiência, aquele que "se dá na relação entre o conhecimento e a vida humana" (p. 26), ou seja, é um saber que não resulta unicamente da condição do sujeito que se informou sobre algo, mas sim do sujeito que experienciou o fato. Nesse sentido, a música não é apenas informação: música é o som que se faz, é a experiência de tocar um instrumento, de compor uma música, de trabalhar em grupo musical e vivenciar todas as suas dinâmicas.

\section{Trabalho autoral}

De acordo com o que já foi discutido neste texto, os músicos entrevistados tiveram, em suas trajetórias, um itinerário semelhante; nenhum deles iniciou a caminhada no campo da música como um artista solo e/ou compositor. Antes de decidirem por ter um trabalho autoral, passaram pelos momentos que até aqui foram descritos; alguns momentos mais lúdicos, em interações sociais, outros, direcionados a uma aprendizagem musical mais sistemática e também dedicam-se a prática da escuta musical de artistas já consagrados, seja por meio do rádio, dos discos ou assistindo apresentações "ao vivo". E, não menos importante, observase uma atuação profissional como músicos de apoio, isto é, um fazer musical baseado em práticas de interpretação de obras já existentes. É nesta trama que, por diferentes caminhos, emerge o compositor e o artista.

A minha primeira oportunidade [...] foi quando fui convidado por um grande declamador gaúcho, chamado Valdemar Camargo, a compor a trilha sonora de seu CD de poesias gaúchas. Tive a liberdade de poder compor melodias de acompanhamento para poesias recitadas. [...] A partir daí, comecei a compor melodias para letras de amigos poetas, com as quais participávamos de festivais nativistas de Música do RS (Graciola). 
Assim, chega um momento em que estes músicos passam a empreender uma carreira musical que não é mais baseada na interpretação de obras conhecidas e/ou apenas como músico de apoio em bandas, conjuntos de baile etc. Para Graciola, isso aconteceu por uma demanda profissional; naquele momento, o músico ainda não estava criando seu trabalho autoral de música instrumental, mas certamente esta prática teve um efeito pedagógico que o ajudará na sua trajetória. Já no relato de Renato Borghetti, observa-se que, após ter tocado em vários festivais, com grupos diferentes, ou seja, ter atuado como instrumentista de apoio, e também depois de tocar em bares e eventos diversos, resolveu gravar um disco:

[...] até uma hora que eu digo: olha, vou gravar um disco [...]. Então, em $83 \mathrm{eu}$ quis gravar um disco, para registrar, mas não para [...] virar artista. Para ter o registro. [...] O primeiro repertório (do primeiro disco), para mim foi fácil, porque foram as músicas que eu mais tocava [...]. A partir do segundo, que já fiquei mais na obrigação, né [...] O primeiro deu muito certo, então o segundo tinha que ser mais [...], já tinha mais "responsa" (Borghetti).

Para Renato, inicialmente, a ideia de gravar um disco teve apenas o objetivo de registrar um trabalho que já vinha fazendo. Segundo o músico, foi só a partir do segundo disco, que se viu "mais na obrigação" de ser um artista, o que o fez se preocupar mais com a ideia de compor. Isto indica a importância de ser um compositor para ser considerado, perante o público e a crítica musical, como um artista. Ou seja: é como se houvesse uma passagem da interpretação (que não deixa de ser uma espécie de criação) para a criação reconhecida como tal. Entretanto, não basta apenas ser um compositor; de acordo com Caminha, é preciso registrar, é preciso criar o álbum, gravar o disco.

[...] tá, existe essas mídias que nós falamos, e tal (vídeos, áudios, internet etc.). Mas, o cara que vai iniciar um trabalho tem que ter um CD, um primeiro disco. [...] Ainda é indispensável, principalmente porque começa. Então, a gurizada faz muito isso, vai para um estúdio, gravar um áudio bacana, bonito e coloca no youtube. Mas não implementa um início, não batiza uma carreira solo (Caminha).

Há aqui a demonstração de algumas normativas que servem como uma condição de emergência do artista. Não basta apenas compor, e também não basta apenas "postar" em redes sociais um vídeo ou um áudio; é preciso (ainda) gravar um disco. O disco, aqui, assume centralidade neste processo, sendo ele uma espécie de consolidação, mesmo que temporária, da identidade do artista, bem como das sonoridades que o representam. Vale ressaltar que, ao falar sobre o disco (seja o CD ou o vinil, entre outros formatos), não estamos nos referindo somente ao suporte físico que é utilizado para o armazenamento de áudio, mas sim a uma forma artística musical que, através da ideia de "álbum”, empreende ações de criação de músicas ligadas à indústria fonográfica.

Entendemos o álbum de música como aquele produto da indústria fonográfica que circunscreve sonora e tematicamente a criação dos músicos e apresenta uma série 
de características, tais como: a ordem predeterminada das faixas, a incorporação de elementos gráficos, como fontes e imagens para compor a capa, contracapa, encarte e uma certa unidade sonora (Waltenberg, 2016, p.186).

Para Caminha, o disco, a partir de um conceito de álbum, ainda é fundamental, por ser um artefato que permite ao artista "montar" a sua identidade, servir como cartão de visita, isto é, apresentar as suas escolhas estéticas, materializadas em um artefato sonoro e visual, possibilitando demonstrar ali quais elementos o representam. Isto auxilia o consumo simbólico desta música, no sentido de organizar "um conjunto de processos sócio-culturais em que se realizam a apropriação e o uso dos produtos" (Canclini, 1999, p. 77). Neste sentido, o álbum é um importante elemento nos processos de constituição das identidades, pois seria capaz de sintetizar e categorizar as sonoridades dos músicos, mesmo que de modo contingente, sendo mais uma instância de negociação/adequação do trabalho autoral do músico a um determinado gênero musical.

Os gêneros seriam então modos de mediação entre as estratégias produtivas e o sistema de recepção, entre os modelos e os usos que os receptores fazem desses modelos através das estratégias de leitura dos produtos midiáticos. Antes de ser um elemento imanente aos aspectos estritos da música, o gênero estaria presente no texto através de suas condições de produção e consumo (Janotti Jr, 2006, p.06).

Ao refletir a respeito das condições de produção e consumo da Música Instrumental Gaúcha, é importante considerar os festivais nativistas ${ }^{6}$ como um elemento central nesta trama. Nesses eventos, os quais têm um caráter competitivo, as músicas são, na maioria dos casos, autorais e inéditas, e apresentam como peculiaridade a produção de álbuns a cada edição. A participação dos músicos que não são autores/compositores, se dá na função de instrumentista e/ou vocalista. Todos os entrevistados desta pesquisa narraram ter participado desses eventos seja como compositor, como instrumentista ou como arranjador musical. Nesse contexto, o músico tem a oportunidade de agir no campo criativo da música, estudando e aplicando conhecimentos que vão servir como base para empreender uma carreira artística própria.

Eu comecei a compor para festivais (nativistas). Antes da faculdade eu já ia a muitos festivais. Eu já tinha passado por quase todos (festivais) nessa época. Daí eu comecei a compor, e passava música minha, e nisso vem o autoral. Aí, em um festival de Pelotas, onde eu compus uma música instrumental, pela primeira vez, e mandei. Uma valsa chamada Flutuando. [...] Já com arranjo meu, escrevi tudo, violão, contrabaixo e flauta, uma grade com três instrumentos. [...] Daí depois eu comecei a estudar composição com o José Homero em Pelotas, e aí veio um professor, [...] que veio da Europa, [...] , e eu estudei composição mais a fundo, eu estudei Tchaikovsky, transcrição [...]. E aí, nesse período, eu compus o "Bugio de Concerto" [...], e comecei a desenvolver uma linguagem de violão solo, já pensando neste disco, que foi o primeiro disco que foi o "Cordas ao Sul". Aí eu comecei a compor, e a arranjar coisas que eram de acordeon para o violão, daí 
aquela coisa do Borghetti, do Albino Manique [...], com a minha maneira de tocar. Claro, eu já tinha referência, do Mario Barros, do Lucio Yanel, eu tirava as coisas deles de ouvido, dos discos. Era uma pesquisa de técnica e de sonoridade (Marques).

Esse fragmento demonstra que vivenciar esse cenário contribui para a emergência de um compositor/artista na medida em que a MIG pode ser produtiva na organização e difusão de conhecimentos. Vemos que, no caso do violonista Maurício Marques, o contexto dos festivais nativistas o ajudou a desenhar seus aprendizados. Participar de um festival de caráter nativista como compositor de música instrumental estimulou este sujeito a desenvolver um trabalho autoral, apresentando como fonte de estudos tanto os artefatos escolares quanto os culturais.

A composição "Bugio de Concerto" é um ótimo exemplo para observarmos a estratégia que Maurício utiliza para constituir uma sonoridade para o seu trabalho; percebe-se que o músico utiliza seus estudos de composição erudita e também um dos ritmos usados pela música gaúcha, e ainda opta por adaptar estes elementos para ser executado ao violão, o que demonstra, mesmo que de modo contingente, como os músicos "exacerbam esses cruzamentos e os convertem em eixos conceituais de seus trabalhos" (Canclini, 2001 p. 23). Esse é um processo criativo realizado a partir de transgressões e de tensionamentos entre diferentes modos de fazer música; a busca por uma sonoridade exige do músico utilizar seus conhecimentos, explorar outros que ainda não sabe, selecionar, organizar e empreender um novo produto (musical).

\section{Considerações finais}

Ao realizar o estudo a respeito das pedagogias culturais que atuam na aprendizagem dos instrumentistas da Música Instrumental Gaúcha, procuramos mostrar o modo como diferentes instâncias e artefatos articulados por este gênero musical têm efeitos na promoção de situações de aprendizagem e na produção de saberes. Na análise do material foi possível constatar que as aprendizagens vão acontecendo durante a trajetória destes sujeitos, os quais estão inseridos em um contexto que não é escolar, mas que apresenta uma organização de conteúdos musicais e culturais que sugerem quais (e como) instrumentos musicais, gêneros e ritmos musicais etc., devem ser utilizados.

Observamos que, por motivos diferentes, os músicos - já impregnados por uma ambiência mais geral da chamada cultura 'gaúcha' - desenvolvem seus aprendizados ao construírem uma carreira de artista/compositor na qual, além de estudarem o instrumento e diferentes repertórios musicais, são levados a criarem um trabalho próprio/autoral. Este trabalho exige determinados conhecimentos, que vão além do estudo da técnica, da teoria musical, do estudo dos diferentes gêneros; agora é necessário ter as suas próprias músicas, criar a sua própria identidade musical, encontrar a sua sonoridade. Este é um processo criativo que desencadeia uma série de ações em que o sujeito precisa aprender como compor músicas dentro do universo simbólico da MIG. 
Acreditamos que as instâncias e os artefatos culturais aqui discutidos contribuem para as aprendizagens musicais e a consequente emergência de um artista, cuja escuta, por sua vez, possivelmente contribuirá para a constituição de outros instrumentistas. Certamente, tais processos, ainda que bastante específicos de um contexto regional, exemplificam a afirmação de Camozzatto, Carvalho e Andrade (2016, p. 12):

Há, nesse sentido, muitos espaços e artefatos disponíveis para que as pedagogias funcionem e, com isso, possam propiciar que os sujeitos aprendam a se modificar e estabelecer relações consigo e com o mundo que os cerca.

Por fim, é possível argumentar que estes músicos aprendem em ambientes sociais/culturais, aprendem em aulas de música, aprendem escutando o rádio e os discos (CDs etc.), aprendem também tocando com outros músicos e aprendem compondo, construindo uma carreira, gravando discos etc. Com isso, vimos que os aprendizados musicais, os modos de ser, os modos de soar destes sujeitos acontecem também fora dos muros escolares, e, com isso, pensamos que devemos estar atentos, analisar e nos apropriar dessas outras possibilidades pedagógicas, que podem ser significativas também para pensar a educação escolar.

\section{Referências}

ANDRADE, Paula Deporte de; COSTA, Marisa Vorraber. Nos rastros do conceito de pedagogias culturais: invenção, disseminação e usos. Educação em Revista. Belo Horizonte. |n.33, p. 1-23. 2017

CAMOZZATTO, Viviane; CARVAlHO, Rodrigo Saballa de; ANDRADE, Paula Deporte de. (orgs.) Pedagogias culturais - a arte de produzir modos de ser e viver na contemporaneidade. Curitiba: Appris, 2016.

CANCLINI, Néstor Garcia. Culturas Híbridas. São Paulo: EdUSP, 2008. 1999.

Consumidores e Cidadãos: conflitos multiculturais da globalização. Rio de Janeiro: EdUFRJ,

FIRTH, Simon 2003. Música e identidade. In: HALL, Stuart; GAY, Paul du (comps). Cuestiones de identidade cultural. Buenos Aires: Amorrortu, 2003.

FREITAS, Letícia R. de; SILVEIRA, Rosa M. Hessel. A figura do gaúcho e a identidade cultural latinoamericana. Revista Educação. Porto Alegre. Ano XXVII, n. 2 (53), p. 263-281 mai/ago 2004.

JANOTTI JR, Jeder. Mídia, música popular massiva e gêneros musicais: a produção de sentido no formato canção a partir de suas condições de produção e reconhecimento. In: XV Encontro da Compós, 2006, BauruSP: p. $1-11$.

LARROSA, Jorge. Notas sobre a experiência e o saber da experiência. Revista Brasileira de Educação, Rio de Janeiro, $\mathrm{n}^{\circ} 19$, jan/abr., p. 20-28, 2002.

SILVA, Tomaz Tadeu da. Documentos de Identidade: uma introdução às teorias do currículo. 2 ed. Belo Horizonte: Autêntica, 2004.

STEINBERG, Shirley R. Kindercultura: a construção da infância pelas grandes corporações. In: SILVA, Luiz Heron da; AZEVEDO, José Clóvis de; SANTOS, Edmilson Santos dos (Orgs.). Identidade Social e a Construção do Conhecimento. Porto Alegre: SMED, 1997. p.98-145. 
WALTENBERG, Lucas. Novas configurações do álbum de música na cultura digital: o caso do aplicativo "Biophilia", Revista Crítica de Ciências Sociais, n. 109, p. 185-202, maio 2016. Disponível em: http://www.scielo.mec.pt/pdf/rccs/n109/n109a09.pdf. Acesso em: 20 de novembro de 2020.

\section{Correspondência}

Felipe Batistella Alvares: Licenciado em Música e Mestre em Educação pela UFSM e Doutor em Educação pela UFRGS. Atua como professor no IFRS Campus Sertão nas áreas de Educação Musical, Educação e Produção Multimídia.

E-mail: felipe.alvares@ sertao.ifrs.edu.br

Rosa Maria Hessel Silveira: Mestre em Letras e Doutora em Educação pela UFRGS. Professora titular aposentada da Faculdade de Educação, atuou no Programa de Pós-Graduação em Educação, orientando Mestrado e Doutorado na linha de Estudos Culturais em Educação.

E-mail: rosamhs@gmail.com

Texto publicado em Currículo sem Fronteiras com autorização dos autores. 